\title{
HUBUNGAN KADAR IODIUM GARAM KONSUMSI DAN TINGKAT KONSUMSI IODIUM DENGAN KADAR EKSKRESI IODIUM URIN (EIU) WANITA USIA SUBUR
}

\author{
Relationship Between Iodine Level Salt Consumption Iodine Levels With \\ Levels Urinary Excretion Of Iodine (UEI) On Women Childbearing Age
}

\author{
Heppy Diah Apika ${ }^{1}$, Endo Dardjito ${ }^{2}$, Dyah Umiyarni Purnamasari ${ }^{3}$ \\ ${ }^{1}$ Puskesmas Purwokerto Timur II Kabupaten Banyumas \\ ${ }^{2}$ Program Studi Gizi Fakultas Ilmu-Ilmu Kesehatan Unsoed \\ ${ }^{3}$ Jurusan Kesehatan Masyarakat Fakultas Ilmu-Ilmu Kesehatan Unsoed \\ heppy_apika@gmail.com
}

\begin{abstract}
The purpose of this study analyze the relationship between the iodine content of salt consumption and the level of consumption of iodine levels in women of childbearing age UIE. The study was observational with cross sectional design. The research location in the village of Kebumen, Baturraden subdistrict, Banyumas. Subjects were 38 selected by simple random sampling technique. The consumption level of iodine was measured by the method of Food Recall $2 \times 24$ hours. Salt iodine content was measured by iodometric titration method and UIE levels measured by acid digestion method in the laboratory BP2GAKI Magelang. Data analysis using spearman correlation. A total of $71.1 \%$ women of childbearing age using the iodine content of salt consumption of $<30 \mathrm{ppm}$. The consumption level of iodine less subject category (86.8\%). UIE levels by an average of $156.50 \mu \mathrm{g} / \mathrm{L}$ category of normal iodine intake. There was no relationship with the iodine content of salt UIE levels ( $p=0.671)$. No correlation with levels of iodine consumption levels UIE $(p=0.586)$. Levels of UIE women of childbearing age are not affected by the iodine content of salt and iodine consumption levels.
\end{abstract}

Keywords: Iodized salt, consumption levels, UIE

\begin{abstract}
ABSTRAK
Tujuan penelitian ini adalah menganalisis hubungan kadar yodium konsumsi garam dan tingkat konsumsi kadar yodium pada wanita usia subur UIE. Penelitian ini bersifat observasional dengan rancangan cross sectional. Lokasi penelitian di desa Kebumen, Kecamatan Baturraden, Banyumas. Subjek penelitian dipilih dengan teknik simple random sampling. Tingkat konsumsi yodium diukur dengan metode Food Recall 2x24 jam. Kandungan garam yodium diukur dengan metode titrasi iodometrik dan tingkat UIE yang diukur dengan metode pencernaan asam di laboratorium BP2GAKI Magelang. Analisis data menggunakan korelasi spearman. Sebanyak $71,1 \%$ wanita usia subur menggunakan kandungan yodium konsumsi garam $<30 \mathrm{ppm}$. Tingkat konsumsi kategori subjek kurang yodium (86,8\%). Tingkat UIE rata-rata 156,50 $\mu \mathrm{g} / \mathrm{L}$ kategori asupan yodium normal. Tidak ada hubungan dengan kadar yodium kadar garam UIE $(p=0,671)$. Tidak ada korelasi dengan tingkat kadar konsumsi yodium UIE $(\mathrm{p}=0,586)$. Tingkat wanita UIE pada usia subur tidak terpengaruh oleh kadar yodium tingkat konsumsi garam dan yodium.
\end{abstract}

Kata kunci: garam beryodium, tingkat konsumsi, UIE 


\section{PENDAHULUAN}

Di Indonesia masalah Gangguan Akibat Kekurangan Iodium (GAKI) masih menjadi persoalan kesehatan masyarakat yang serius mengingat dampaknya secara langsung dapat mempengaruhi kualitas sumber daya manusia. Hasil survei di seluruh Indonesia menunjukkan peningkatan prevalensi Total Goiter Rate (TGR) dari 9.8\% pada tahun 1998 menjadi sebesar 11.1\% pada tahun 2003 (RAN GAKI 2004). Prevalensi Total Goiter Rate (TGR) di Provinsi Jawa Tengah pada tahun 1998 yaitu sebesar $20.5 \%$ dalam ketegori endemik berat (Dinkes Provinsi Jateng 2007). Pada tahun 2004 terjadi penurunan signifikan prevalensi TGR di Provinsi Jawa Tengah dengan perolehan 9.68\% dalam kategori endemik ringan (Dinkes Provinsi Jateng 2004).

Hasil survei Total Goiter Rate (TGR) di Kabupaten Banyumas tahun 2007 diperoleh hasil sebesar $11.4 \%$ dalam kategori endemik ringan GAKI (Dinkes Kabupaten Banyumas 2007). Penurunan signifikan terjadi pada tahun 2014 yang menunjukan bahwa prevalensi Total Goiter Rate (TGR) di Kabupaten Banyumas sebesar $0.21 \%$ dan sudah dianggap dalam daerah non endemik
GAKI karena $<5 \%$ (Dinkes Kabupaten Banyumas 2014). Meskipun sudah dianggap dalam kategori non endemik GAKI, perhatian dan penanganan terhadap GAKI tetap diperlukan. Mengingat bahwa kejadian GAKI dapat diartikan sebagai suatu fenomena gunung es dimana gondok endemik, kreatin endemik dan hipotiroidisme muncul di permukaan secara klinis, sedangkan yang tersembunyi jauh lebih banyak terutama yang tergolong di dalam "minimal brain damage" (Arisman 2010).

Faktor-faktor yang berpengaruh terhadap kejadian GAKI diantaranya defisiensi iodium. Defisiensi iodium dapat disebabkan karena rendahnya pola konsumsi makanan yang mengandung iodium, seperti makanan laut dan tidak tersedianya garam beriodium (Gibney et al. 2009). Gangguan akibat kekurangan iodium dapat menyerang berbagai tingkatan usia diantaranya adalah pada Wanita Usia Subur (WUS) (Kemenkes RI 2015). Penelitian Bashir et al. (2012) menyatakan bahwa asupan iodium memiliki peranan yang penting pada wanita usia subur produktif untuk mencegah gangguan tiroid yang dapat menimbulkan risiko pada masa kehamilan, seperti keguguran, kematian janin, kretinisme dan keterbelakangan mental pada bayi yang dilahirkannya. 
Salah satu indikator penentuan status GAKI adalah dengan menggunakan pemeriksaan kadar iodium dalam urin untuk mengetahui kecukupan iodium seseorang. Ekskresi Iodium Urin (EIU) paling banyak digunakan sebagai marker biokimia untuk GAKI karena lebih obyektif, sederhana, murah dan iodium yang telah dikonsumsi lebih dari 90\% akan diekskresi oleh tubuh lewat urin sehingga dapat merefleksikan asupan iodium (EFSA 2014). Hasil penelitian yang dilakukan oleh Mutazalimah et al. (2013) menyatakan bahwa terdapat hubungan antara asupan iodium dan ekskresi iodium urin subjek, jika asupan iodium cukup, ekskresi iodium urin juga akan optimal. Selain itu, hasil penelitian Donny et al. (2013) menunjukkan bahwa semakin tinggi kadar iodium dalam garam beriodium maka kebutuhan iodium semakin tercukupi yang diinterpretasikan dari kadar iodium dalam urin. Berdasarkan uraian diatas maka penelitian ini ingin mengetahui apakah ada hubungan antara kadar iodium garam konsumsi dan tingkat konsumsi iodium dengan kadar ekskresi iodium urin pada wanita usia subur Di Desa Kebumen Kecamatan Baturraden. Manfaat penelitian ini khususnya bagi institusi pelayanan kesehatan diharapkan agar dapat memberikan masukan informasi dan dapat menjadi bahan pertimbangan dalam upaya memperbaiki dan meningkatkan pelaksanaan program penanggulangan GAKI pada wanita usia subur.

\section{METODE}

\section{Desain, tempat dan waktu}

Jenis penelitian ini merupakan studi analitik observasional dengan pendekatan rancangan Cross-Sectional untuk menganalisis hubungan variabel satu dengan variabel lain dalam satu populasi diukur dalam waktu yang sama (Notoatmodjo 2010). Penelitian ini dilaksanakan di Desa Kebumen, Kecamatan Baturraden yang dilaksanakan pada Maret - Agustus 2016.

\section{Jumlah dan cara pengambilan subjek}

Populasi dalam penelitian ini seluruh wanita usia subur berusia 15-49 tahun berdomisili di Desa Kebumen, Kecamatan Baturraden, Kabupaten Banyumas yang berjumlah 806 orang. Sampel pada penelitian ini berjumlah 38 sampel diperoleh dengan teknik simple random sampling. Kriteria inklusi sampel penelitian yaitu wanita usia subur yang tinggal di daerah penelitian minimal 1 tahun, wanita yang berusia 15 - 49 tahun, bersedia menjadi responden dan datang 
pada waktu pengambilan data penelitian.

Sedangkan kriteria eksklusi yaitu wanita usia subur dalam keadaan sakit, wanita usia subur sedang hamil.

\section{Jenis dan Cara Pengumpulan Data}

Data yang dikumpulkan yaitu data karakteristik responden menggunakan kuesioner, Kadar iodium garam konsumsi dengan metode titrasi iodomteri yang dianalisis oleh Laboratorium Balai Penelitian dan Pengembangan Gangguan Akibat Kekurangan Iodium (BP2GAKI) Magelang. Konsumsi makanan yang mengandung iodium dengan metode food recall 2 x 24 dengan hari yang tidak berurutan. Ekskresi Iodium Urin (EIU) dengan metode acid digestion menggunakan larutan amonium persulfat yang akan dianalisis langsung oleh Laboratorium (BP2GAKI) Magelang.

\section{Pengolahan dan Analisis Data}

Data kadar iodium garam konsumsi, tingkat konsumsi iodium dan kadar ekskresi iodium urin diuji kenormalitasannya menggunakan uji shapiro wilk. Hasil uji normalitas diperoleh bahwa data tidak berdistribusi normal, oleh karena itu dilanjutkan dengan uji korelasi spearman.

\section{HASIL DAN PEMBAHASAN}

\section{Karakteristik Responden}

Data karakteristik responden penelitian antara lain berdasarkan umur, pendidikan, pekerjaan dan jumlah anggota keluarga. Data karakteristik responden penelitian dapat dilihat pada Tabel 1.

Tabel 1. Karakteristik Responden Penelitian berdasarkan Umur, Pendidikan, Pekerjaan dan Jumlah Anggota Keluarga

\begin{tabular}{lcc}
\hline \multicolumn{1}{c}{ Variabel } & Jumlah & Persentase (\%) \\
\hline Usia & & \\
20-35 & 26 & 68.4 \\
$>35$ & 12 & 31.6 \\
Pendidikan Terakhir & & \\
$\quad$ Dasar & 24 & 63.1 \\
Menengah & 12 & 31.6 \\
Tinggi & 2 & 5.3 \\
Pekerjaan & & \\
IRT & 32 & 84.2 \\
Buruh & 1 & 2.6 \\
Wiraswasta & 4 & 10.5 \\
PNS & 1 & 2.6 \\
Jumlah Anggota Keluarga & & \\
$\quad<4$ (Keluarga Kecil) & 17 & 44.7 \\
5-6 (Keluarga Sedang) & 18 & 47.4 \\
>7 (Keluarga Besar) & 3 & 7.9 \\
\hline Sumber : Data Primer Terolah 2016 & &
\end{tabular}

Sumber : Data Primer Terolah, 2016 
Tabel 1 menunjukkan bahwa responden penelitian sebagian besar (68.4\%) berusia 20-35 tahun. Pendidikan terakhir responden penelitian paling banyak adalah pendidikan dasar $(63.1 \%)$. Status pekerjaan responden penelitian hampir semua (84.2\%) dalam kategori Ibu Rumah Tangga (IRT). Berdasarkan pengkategorian jumlah anggota keluarga responden penelitian berada dalam kategori keluarga sedang (5-6 orang) yaitu sebesar (47.4\%).

Tabel 2. Kategori Proses Penyimpanan Garam Responden

\begin{tabular}{|c|c|c|}
\hline Variabel & Jumlah & Persentase \\
\hline \multicolumn{3}{|l|}{ Penyimpanan Garam } \\
\hline Sesuai & 31 & 81.6 \\
\hline Tidak Sesuai & 7 & 18.4 \\
\hline & 38 & $100 \%$ \\
\hline
\end{tabular}

Sumber : Data Primer Terolah, 2016

Berdasarkan Tabel 2 di atas menunjukkan bahwa sebanyak $81.6 \%$ responden penelitian sudah melakukan proses penyimpanan garam yang sesuai meliputi cara penyimpanan, penggunaan wadah penyimpanan, peletakan garam dengan sumber perapian dan paparan sinar matahari. Tabel 3 tersebut dapat diketahui bahwa sebagian besar responden (65.8\%) dalam kategori pengeluaran pangan rendah $<\mathrm{Rp}$ 302.267.

Tabel 3. Pengeluaran Pangan Responden

\begin{tabular}{|c|c|c|}
\hline Variabel & Jumlah & Persentase (\%) \\
\hline \multicolumn{3}{|l|}{ Pengeluaran pangan } \\
\hline Tinggi (>Rp 302.267,-) & 13 & 34.2 \\
\hline Rendah $(<\operatorname{Rp} 302.267,-)$ & 25 & 65.8 \\
\hline & 38 & $100 \%$ \\
\hline
\end{tabular}

Sumber : Data Primer Terolah, 2016

Tabel 4 menunjukkan bahwa sebagian besar $(71.1 \%)$ kadar iodium garam konsumsi yang digunakan responden pada penelitian ini dalam kategori tidak memenuhi syarat karena $<30$ ppm dari standar nasional yang telah ditentukan
Depkes RI (2011) untuk kualitas garam beriodium. Hasil analisis univariat untuk distribusi statistik kadar iodium garam konsumsi menunjukkan bahwa rata-rata kadar iodium garam konsumsi responden diperoleh hasil sebesar 20.97 ppm dengan 
nilai minimum $5.24 \mathrm{ppm}$ dan nilai maksimum sebesar $52.43 \mathrm{ppm}$.

Tabel 4. Pengkategorian Kadar Iodium Garam Konsumsi Responden

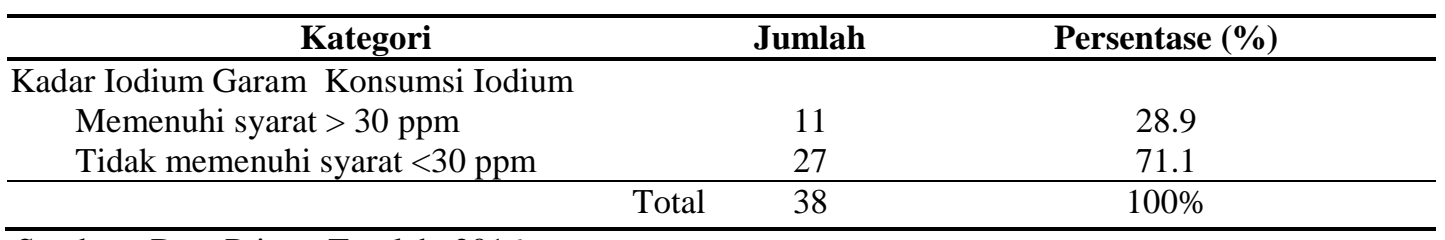

Sumber : Data Primer Terolah, 2016

Pada Tabel 5 menunjukkan bahwa sebagian besar $(86,8 \%)$ responden penelitian dalam kategori tingkat konsumsi iodium kurang. Hasil analisis univariat untuk distribusi statistik tingkat konsumsi iodium menunjukkan bahwa rata-rata tingkat konsumsi iodium responden penelitian diperoleh hasil sebesar $13,3 \%$ dengan nilai minimum $1,70 \%$ dan nilai maksimum $86,0 \%$.

Tabel 5. Pengkategorian Tingkat Konsumsi Iodium

\begin{tabular}{|c|c|c|}
\hline Kategori & Jumlah & Persentase (\%) \\
\hline \multicolumn{3}{|l|}{ Tingkat Konsumsi Iodium } \\
\hline Kurang $(<80 \%)$ & 33 & 86.8 \\
\hline Sedang $(80 \%-<100 \%)$ & 5 & 13.2 \\
\hline & 38 & $100 \%$ \\
\hline
\end{tabular}

Sumber : Data Primer Terolah, 2016

$$
\text { Berdasarkan Tabel } \quad 6 \quad \text { kadar ekskresi iodium urin menunjukkan }
$$
menunjukkan bahwa responden nilai rata-rata kadar ekskresi iodium urin penelitian paling banyak (36.8\%) dalam responden sebesar $156.50 \mu \mathrm{g} / \mathrm{L}$ dengan kategori kadar ekskresi iodium urin ideal nilai terendah sebesar $10 \mu \mathrm{g} / \mathrm{L}$ dan nilai atau normal. Hasil analisis univariat tertinggi sebesar $463 \mu \mathrm{g} / \mathrm{L}$.

Tabel 6. Pengkategorian Kadar Ekskresi Iodium Urin Responden

\begin{tabular}{|c|c|c|}
\hline Kategori & Jumlah & Persentase $(\%)$ \\
\hline Defisiensi iodium yang berat $(<20 \mu \mathrm{g} / \mathrm{L})$ & 1 & 2.6 \\
\hline Defisiensi iodium yang sedang $(20-49 \mu \mathrm{g} / \mathrm{L})$ & 3 & 7.9 \\
\hline Defisiensi iodium yang ringan $(50-99 \mu \mathrm{g} / \mathrm{L})$ & 6 & 15.8 \\
\hline Asupan iodium yang ideal $(100-199 \mu \mathrm{g} / \mathrm{L})$ & 14 & 36.8 \\
\hline $\begin{array}{l}\text { Lebih dari asupuan iodium yang adekuat (dapat } \\
\text { meningkatkan resiko hipertiroidisme }(200-299 \mu \mathrm{g} / \mathrm{L})\end{array}$ & 8 & 21.1 \\
\hline Asupan iodium yang berlebihan $(>300 \mu \mathrm{g} / \mathrm{L})$ & 6 & 15.8 \\
\hline 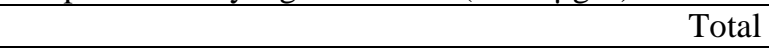 & 38 & $100 \%$ \\
\hline
\end{tabular}


Hubungan Kadar Iodium Garam

Konsumsi dengan Kadar Ekskresi

\section{Iodium Urin}

Hasil uji korelasi spearman dapat dilihat pada Tabel 7 yang menunjukkan bahwa tidak terdapat hubungan antara kadar iodium garam konsumsi dengan kadar ekskresi iodium urin subjek penelitian dengan koefisien korelasi (r) sebesar 0.071 dan nilai $\mathrm{p}>0.05$ sehingga dapat disimpulkan bahwa. Hasil penelitian ini sejalan dengan penelitian
Susiana (2011) yang menunjukkan bahwa tidak ada hubungan antara kadar iodium garam konsumsi dengan kadar ekskresi iodium urin dengan nilai $p$ value 0,146 . Namun, hasil penelitian ini tidak sejalan dengan penelitian Donny et al. (2013) yang menunjukkan bahwa ada hubungan bermakna antara kadar iodium dalam garam beriodium di rumah tangga dengan kecukupan iodium berdasarkan nilai EIU dengan nilai $\mathrm{p}<0.01$.

Tabel 7. Hubungan antara Kadar Iodium Garam Konsumsi dengan Kadar Ekskresi Iodium

\begin{tabular}{lcccc}
\multicolumn{1}{c}{ Variabel } & $\begin{array}{c}\text { Jumlah } \\
(\mathbf{n})\end{array}$ & $\begin{array}{c}\text { Korelasi } \\
(\mathbf{r})\end{array}$ & Nilai p & $\boldsymbol{\alpha}$ \\
\hline $\begin{array}{l}\text { Kadar Iodium Garam Konsumsi } \\
\text { Kadar Ekskresi Iodium Urin }\end{array}$ & 38 & 0.071 & 0.671 & 0.05 \\
\hline Sumber : Data Primer Terolah, 2016 & &
\end{tabular}

Sumber : Data Primer Terolah, 2016

Tidak adanya hubungan bermakna antara kedua variabel tersebut, hal ini dapat terjadi karena urin diambil sewaktu sehingga kurang sensitif untuk menentukan derajat endemitas GAKI di suatu wilayah atau populasi. Pengambilan sampel urin sewaktu pada penelitian ini didasarkan oleh sumber WHO, ICCID, UNICEF (2007) yang menyebutkan bahwa pengambilan urin untuk studi lapangan dapat dilakukan dengan menggunakan urin sewaktu sebab urin 24 jam atau urin pagi sulit didapatkan pada studi lapangan. Menurut EFSA (2014) menyebutkan bahwa profil konsentrasi iodium pagi hari pada anak atau orang dewasa merupakan penilaian adekuat nutrisi iodium pada populasi. Sampel terbaik untuk pemeriksaan ekskresi iodium urin adalah urin 24 jam karena dapat menggambarkan fluktuasi iodium dari hari ke hari. Hal ini sejalan dengan hasil penelitian Laurberg et al. (2007) yang menyatakan bahwa pengambilan sampel urin sebaiknya dilakukan pagi hari, karena dapat menilai kecukupan iodium lebih aktual. Hasil penelitian Johner et al. (2010) menunjukkan bahwa 
kadar ekskresi iodium urin sangat fluktuatif dari waktu ke waktu yang dapat dipengaruhi oleh asupan air atau adanya pengaruh dehidrasi. Dibandingkan dengan asupan cairan biasa, peningkatan asupan volume cairan dapat menyebabkan pengeluaran iodium tambahan, untuk peningkatan volume urin dari satu liter, pengeluaran iodium tambahan sekitar $15 \mathrm{mg} / \mathrm{hari}$ untuk remaja dan wanita dewasa.

Hubungan Tingkat Konsumsi Iodium dengan Kadar Ekskresi Iodium Urin

$\begin{array}{lll}\text { Berdasarkan } & \text { Tabel } & 8\end{array}$ menunjukkan bahwa hasil uji korelasi spearman didapatkan koefisien korelasi (r) sebesar 0.091 dan nilai $\mathrm{p}>0.05$ sehingga dapat disimpulkan bahwa tidak terdapat hubungan antara tingkat konsumsi iodium dengan kadar ekskresi iodium urin responden dengan nilai $\mathrm{p}=$ 0.586. Hasil penelitian ini sejalan dengan penelitian Siti dan Irma (2010) yang menunjukan bahwa tidak ada hubungan antara tingkat konsumsi iodium dengan status iodium wanita usia subur di Desa Selo dengan nilai $\mathrm{p}=0.889$. Namun, hasil penelitian ini berbeda dengan penelitian Mutalazimah et al. (2013) yang menyatakan bahwa terdapat hubungan bermakna antara konsumsi iodium dengan kadar ekskresi iodium urin wanita usia subur dengan nilai $\mathrm{p}=$ 0.033 .

Tabel 8. Hubungan antara Tingkat Konsumsi Iodium dengan Kadar Ekskresi Iodium Urin

\begin{tabular}{|c|c|c|c|c|}
\hline Variabel & $\begin{array}{c}\text { Jumlah } \\
\text { (n) }\end{array}$ & $\begin{array}{c}\text { Korelasi } \\
\text { (r) }\end{array}$ & Nilai p & $\alpha$ \\
\hline $\begin{array}{l}\text { Tingkat Konsumsi Iodium } \\
\text { Kadar Ekskresi Iodium Urin }\end{array}$ & 38 & 0.091 & 0.586 & 0.05 \\
\hline
\end{tabular}

Tidak adanya hubungan antara tingkat konsumsi iodium dengan kadar ekskresi iodium urin dapat dipengaruhi oleh adanya cadangan iodium di kelenjar tiroid maupun di sirkulasi. Manusia mempunyai cadangan iodium organik alami pada kelenjar tiroid, mencapai 8-10 mg dan merupakan suatu cadangan hormon dan tirosin teriodinisasi yang melindungi organisme terhadap periode kekurangan iodium. Dari pool cadangan ini akan dikeluarkan iodium hormonal ke sirkulasi. Iodium hormonal (sebagai $\mathrm{T}_{3}$ dan $\mathrm{T}_{4}$ ) ini sebagian besar berikatan dengan protein pengikat tiroksin serum dan membentuk suatu pool sirkulasi. 
Sebagian $\mathrm{T}_{3}$ dan $\mathrm{T}_{4}$ diambil dan digunakan oleh sel target yang membutuhkan. Pada sel target dan hati, $\mathrm{T}_{3}$ dan $\mathrm{T}_{4}$ tersebut didegradasi dan iodida akan dikembalikan ke cairan ekstraseluler. Iodium di cairan ekstraseluler ini sebagian diambil oleh kelenjar tiroid untuk digunakan kembali dan sebagian diambil oleh ginjal untuk dikeluarkan melalui urin (Guyton dan Hall 2007).

Sebagian besar (86.8\%) subjek penelitian dalam kategori tingkat konsumsi iodium kurang. Hal ini dapat dipengaruhi oleh pengeluaran pangan responden penelitian yang sebagian besar berada dalam kategori pengeluaran pangan rendah (65.8\%). Menurut penelitian Torontju et al. (2005) menyatakan bahwa semakin besar tingkat pengeluaran pangan keluarga maka semakin besar pula jumlah uang yang dialokasikan untuk membeli makanan serta minuman sumber iodium.

\section{KESIMPULAN}

Kesimpulan penelitian ini menemukan bahwa sebagian besar responden penelitian $(71.1 \%)$ dalam kategori penggunaan garam iodium tidak memenuhi syarat $<30 \mathrm{ppm}$. Sebagian besar $(86.8 \%)$ responden dalam kategori tingkat konsumsi iodium kurang. Kadar ekskresi iodium urin rata-rata sebesar $156.50 \mu \mathrm{g} / \mathrm{L}$ dalam kategori asupan iodium normal. Tidak terdapat hubungan antara kadar iodium garam konsumsi dengan kadar ekskresi iodium urin wanita usia subur $(\mathrm{p}=0.671)$. Tidak terdapat hubungan antara tingkat konsumsi iodium dengan kadar ekskresi iodium urin wanita usia subur dengan nilai $(\mathrm{p}=$ 0.586). Saran dalam rangka upaya meningkatkan tingkat konsumsi makanan sumber iodium dan penggunaan garam iodium, diharapkan masyarakat lebih memperhatikan pola konsumsi makanan yang mengandung sumber iodium seperti makanan hasil laut (ikan, cumi-cumi, kerang dan rumput laut) dan lebih memperhatikan penggunaan garam beriodium yang sesuai SNI yaitu >30 ppm yang tertera pada label kemasan garam konsumsi. Dalam rangka upaya meningkatkan kualitas dan penjaminan mutu garam iodium yang beredar dimasyarakat, Dinas kesehatan, Puskesmas setempat dan instansi terkait seperti Dinas Perdagangan dan Perindustrian diharapkan dapat lebih meningkatkan pengawasan dan pemantauan garam beriodium secara rutin dan berkesinambungan. Peneliti lain 
disarankan untuk meneliti lebih banyak faktor lain seperti adanya interaksi dengan zat gizi lain (Vitamin A) yang dapat mempengaruhi kadar ekskresi iodium urin.

\section{DAFTAR PUSTAKA}

Arisman. 2010. Gizi dalam Daur Kehidupan: Buku Ajar Ilmu Gizi. Buku Kedokteran EGC. Jakarta.

Bashir S. Shabbir I. Hussain R, Islam M, Aasim M. 2012. Thyroid status and urinary iodine levels in women of endemic goiter area.Pakistan Journal Medical Respiratory. 51(4):136-138.

Dinas Kesehatan Kabupaten Banyumas 2007. 2014. Laporan Tahunan Program Perbaikan Gizi Dinkes Banyumas. Purwokerto.

Dinas Kesehatan Provinsi Jawa Tengah 2004. 2007. Profil kesehatan Jawa Tengah. Dinas Kesehatan Provinsi Jawa Tengah. Semarang.

Donny K, Mulyantoro, Muhammad H, Endro B. 2013. Hubungan Kadar Iodium Dalam Garam Beriodium Di Rumah Tangga Dengan Kecukupan Iodium Berdasarkan Nilai Ekskresi Iodium Urin (EIU) Pada Wanita Usia Subur. Balai Litbang GAKI Magelang.

European Food Safety Authority. 2014. Scientific Opinion on Dietary Reference Values for Iodine. EFSA Journal. Parma. Italy. 12 (5) $: 2$.

Gibney MJ, Margetts, Barrie M, Kearney, Jhon, M, Arab L. 2009. Gizi Kesehatan Masyarakat. EGC. Jakarta.

Johner SA, Shi L, Remer T. 2010. Higher urine volume results in additional renal iodine loss. Journal Publication Media. US National Library of Medicine National Instituties of Health. 20 (12): 1391-1397.
Laurberg P, Andersen S, Bjarnadottir RI, Carle, A, Hreidarsson A, Knudsen N, Ovesen L, Pedersen I, Rasmussen L. 2007. Evaluating iodine deficiency in pregnant women and young infants-complex physiology with a risk of misinterpretation. Journal Public Health Nutrition. 10: 1547-1552

Mutalazimah SA, Budi M, Bhisma M, Saifuddin A. 2013. Asupan Yodium, Ekskresi Yodium Urine, dan Goiter pada Wanita Usia Subur di Daerah Endemis Defisiensi Yodium. Jurnal Kesehatan Masyarakat Nasional. 8 (3) :133- 137.

Ritanto MJ. 2003. Faktor Resiko Kekurangan Iodium Pada Anak Sekolah Dasar Di Kecamatam Selo Kabupaten Boyolali. Jurnal GAKI Indonesia. 4 (2).

Septia DS. 2012. Faktor-Faktor yang Berhubungan Dengan Perilaku Penggunaan Garam Beriodium Di 15 Kabupaten/Kota Indonesia. Skripsi. Program studi Ilmu Gizi, Depok.

Siti Z dan Irma Y. 2010. Hubungan Tingkat Konsumsi Zat Gizi Dengan Status Iodium Pada Wanita Usia Subur Di Daerah Endemik GAKI. Jurnal Kesehatan. ISSN 1979-7621, 3 (1) : 67.

Susiana SL. 2011. Faktor-faktor yang berhubungan dengan Ekskresi Yodim Urin (EYU) pada anak sekolah dasar di SDN 1 Sumberejo Kec. Randublatung, Kab. Blora. Skripsi. Program Studi Ilmu gizi fakultas kedokteran UNDIP. Semarang

Torontju Sultan A, Hamam H, Toto S. 2005. Faktor Sosial Ekonomi yang Berhubungan dengan Tingkat Asupan Zat Iodium Pada Ibu Hamil Di Daerah Endemik. Journal BKM, 221 (3) : 87-96.

Zimmermann MB. 2009. Iodine Deficiency In Pregnancy and the effects of maternal iodine supplementation on the off spring. American Journal of Clinical Nutrition. 89: 668-670. American Society for Nutrition. USA. 